\title{
PERANAN RELATIONAL BENEFITS DAN PERCEIVED VALUE DALAM MENINGKATKAN TRUST DAN LOYALITAS PELANGGAN KLINIK KECANTIKAN
} (Studi Pada Miracle Aesthetic Clinic Malang)

\author{
Dexi Triadinda ${ }^{1}$, Astrid Puspaningrum ${ }^{2}$, Ananda Sabil Hussein ${ }^{3}$ \\ Fakultas Ekonomi dan Bisnis Universitas Brawijaya ${ }^{123}$ \\ Email:dexidinda@gmail.com
}

\begin{abstract}
This study analyzed the influence of relational benefits and perceived value in increasing customer trust and loyalty. This study used the data of 130 questionnaires with purposive sampling as the sampling method performed on Miracle Aesthetic beauty clinic in Malang. The population was all customers of Miracle Clinic who were currently in Miracle Clinic. The data analysis instrument was Structural Equation Modeling (SEM) on program SmartPLS version 2.0. The analysis result showed that relational benefits had the highest influence on trust and loyalty. Perceived value influenced the increase of customer trust and loyalty. In this study, trust also increased customer loyalty and increase the influence of relational benefits on loyalty and perceived value on loyalty partially. Loyal customer contributed to Miracle by performing indirect marketing through word of mouth. Then, customers made Miracle Clinic in Malang their main preference in beauty service. The managerial implication suggested by this study is emphasizing on the implementation of relational benefits and increasing perceived value of old and new customers so that the customers trust the company more and be loyal.
\end{abstract}

Keywords: customer loyalty, perceived value, relational benefits, , trust

\begin{abstract}
Abstrak : Penelitian ini menganalisis pengaruh relational benefits dan perceived value dalam meningkatkan trust dan loyalitas pelanggan. Penelitian ini menggunakan data 130 kuesioner dengan penentuan sample menggunakan metode purposive sampling yang dikumpulkan dari klinik kecantikan Miracle Aesthetic Malang, sebagai populasinya adalah keseluruhan pelanggan Miracle Clinic yang saat itu sedang berada di Miracle Clinic. Alat analisis data yang digunakan adalah Structural Equation Modelling (SEM) pada program SmartPLS versi 2.0. Hasil analisis menunjukkan bahwa relational benefits yang memiliki pengaruh tertinggi terhadap trust dan loyalitas. Perceived value memiliki pengaruh terhadap peningkatan trust dan loyalitas pelanggan. Dalam penelitian ini trust juga mampu meningkatkan loyalitas pelanggan serta meningkatkan pengaruh antara relational benefits terhadap loyalitas dan perceived value terhadap loyalitas secara parsial. Pelanggan yang loyal memberikan kontribusi terhadap Miracle dengan melakukan pemasaran secara tidak langsung yaitu word of mouth, selanjutnya pelanggan menjadikan Miracle Clinic Malang sebagai preferensi utama dalam memilih jasa kecantikan. Implikasi manajerial yang dapat disarankan oleh penelitian ini adalah menitikberatkan pada penerapan relational benefits dan meningkatkan perceived value pelanggan lama maupun pelanggan baru agar pelanggan semakin percaya pada perusahaan dan loyal.
\end{abstract}

Kata Kunci: relational benefits, perceived value, trust, loyalitas pelanggan 


\section{Pendahuluam}

Dalam masa sekarang ini Industri jasa merupakan fenomena yang unik dalam pembangunan nasional suatu bangsa. Semakin maju suatu bangsa, maka semakin besar konstribusi komponen jasa pada struktur pendapatan nasionalnya. Sektor jasa merupakan suatu bidang yang beraneka ragam. Sektor jasa kecantikan kulit diprediksi dapat berkembang dengan baik pada tahun - tahun mendatang, hal ini terbukti dari semakin banyaknya pesaing dalam bisnis sejenis, yang memberikan konsumen banyak pilihan dalam menentukan jasa kecantikan seperti apa yang dibutuhkan. Bisnis kecantikan yang sering disebut Aesthetic Clinic, mempunyai pangsa pasar yang cukup luas serta dapat ditujukan kepada siapa saja, dari kanak- kanak sampai orang tua. Bisnis kecantikan kulit, yang dilihat dari kualitas jasa dan produk atau hasilnya, mempunyai pangsa pasar dan segmen pasar yang konsumennya dapat berasal dari semua kalangan, yang disebabkan adanya kebutuhan ataupun hanya keinginan untuk merawat ataupun merubah penampilannya. Besarnya kebutuhan seseorang untuk merawat diri agar terlihat cantik dan semakin berkembangnya gaya hidup kaum wanita, pada akhirnya memberikan pengaruh yang besar bagi pesatnya perkembangan industri kecantikan di Indonesia.

Peluang besar untuk menggarap bisnis kecantikan ini sudah dijajaki Miracle Aesthetic Clinic sejak tahun 1996. Selama hampir 20 tahun, Miracle kini telah hadir di 13 kota besar Indonesia. Beberapa kota tersebut, antara lain Jakarta, Surabaya, Malang, Bandung, Balikpapan, hingga Manado. Menyikapi persaingan antara klinik kecantikan lainnya, Miracle menitikberatkan untuk menampilkan keunikan yang tidak dimiliki kompetitior. Salah satu keunikan tersebut ada pada kualitas servis yang dihadirkan. Salah satu cabang Miracle Clinic yang ada dikota Malang mengalami perkembangan yang cukup pesat ditandai dengan semakin banyaknya jumlah pelanggan. Dengan pemasaran yang berdasarkan prinsip Relationship Marketing Miracle Clinic berupaya untuk mendapatkan dan mempertahankan pelanggan yang berarti memperlakukan pelanggan dengan baik, meningkatkan layanan inti (core service) perusahaan melalui penambahan nilai.

Persaingan ketat yang kini timbul akibat dari banyaknya perusahaan yang bergerak didalam industri kecantikan terutama klinik kecantikan, akan mempengaruhi sebuah perusahaan yang serupa untuk mempertahankan pangsa pasarnya. Agar dapat bertahan, maka perusahaan tersebut dituntut lebih memperhatikan keinginan, kebutuhan, dan kepercayaan pelanggan terutama pada bagaimana cara untuk mempertahankan loyalitas konsumennya agar dapat memenangkan persaingan.

Loyalitas pelanggan adalah sebuah tujuan akhir dalam rangkaian bisnis sebuah perusahaan, selain dari strategi pemasaran yang tepat serta layanan yang prima. Loyalitas pelanggan merupakan hal yang sangat penting bagi perusahan di era kompetisi bisnis yang semakin ketat seperti saat ini. Salah satu cara yang dapat ditempuh untuk meningkatkan loyalitas pelanggan adalah dengan menentukan strategi yang tepat agar perusahaan tetap mampu bertahan di tengah persaingan, mempunyai keunggulan kompetitif serta dapat meningkatkan profitabilitasnya.

Strategi pemasaran yang melibatkan perusahaan dan pelanggan yang terus mengalami perkembangan, dan relevan dengan situasi dunia bisnis sekarang ini adalah relationship marketing. Strategi relationship marketing diyakini dapat memberikan manfaat bagi pelanggan, dan memungkinkan untuk mempersulit hambatan persaingan bagi pesaing, sehingga memampukan perusahaan untuk meningkatkan loyalitas (Hennig-Thurau dan Klee, 2002). Dalam dunia bisnis modern fokus pemasaran mencerminkan pergerakan perubahan dari pemasaran transaksional ke relationship marketing. Memberikan manfaat dari sebuah hubungan atau relational benefit sesungguhnya dapat menguntungkan kedua belah pihak, baik pelanggan maupun perusahaan (Vincent \& Cynthia, 2013). Oleh karena itu, penelitian ini memiliki tujuan untuk mengetahui pengaruh relational benefits terhadap trust dan loyalitas pelanggan.

Dalam memenuhi tuntutan emosional konsumen semakin meningkat, Miracle Clinic juga memberikan kinerja dari perceived value dengan menyediakan klinik yang berkesan mewah, dan terus mengupayakan kemanjaan bagi para pelanggannya sehingga pelanggan memiliki kesan yang mendalam pada perusahaan.

Selain itu, kepercayaan pelanggan juga merupakan faktor penting dalam membangun komitmen antara perusahaan dan pelanggan. 
Chumpitaz Caceres and Nicholas G. Paparoidamis (2005) menemukan bahwa kepercayaan pelanggan berpengaruh terhadap loyalitas pelanggan. Kepercayaan pelanggan dibutuhkan perusahaan untuk membangkitkan loyalitas pelanggan.

Ada beberapa faktor yang mempengaruhi loyalitas pelanggan, antara lain adalah upaya relationship marketing melalui variable relational benefit, perceived value, dan trust. Dengan kata lain trust yang telah diyakini oleh pelanggan akan sebuah perusahaan akan mampu menggerakan loyalitas pelanggan terhadap perusahaan.

Temuan hasil penelitian terdahulu dan minimnya penelitian pada perusahaan yang tergolong baru menunjukkan hasil yang belum konsisten dan perlunya penelitian lanjutan sehingga hal tersebut menimbulkan adanya research gap dan tujuan dari penelitian ini. penulis ingin mengetahui bagaimana fungsi dari relationship marketing melalui peran relational benefits dan perceived value untuk meningkatkan trust dan loyalitas pelanggan.

\section{Pemasaran Jasa}

Dipandang dari konteks globalisasi, pesatnya pertumbuhan bisnis jasa antar negara ditandai dengan meningkatnya intensitas pemasaran lintas negara serta terjadinya aliansi berbagai penyedia jasa di dunia. Kotler (2009:27) mengemukakan pengertian jasa (service), Jasa adalah setiap tindakan atau kinerja yang ditawarkan oleh satu pihak ke pihak lain yang secara prinsip tidak berwujud dan tidak menyebabkan perpindahan kepemilikan. Produksi jasa dapat terikat atau tidak terikat pada suatu produk fisik. Jasa pada dasarnya adalah seluruh aktifitas ekonomi dengan output selain produk dalam pengertian fisik, dikonsumsi dan diproduksi pada saat bersamaan memberikan nilai tambah dan secara prinsip tidak berwujud (intangible) bagi pembeli pertamanya.

\section{Relationship Marketing}

Pemasaran relasional (relationship marketing) adalah suatu filosofi menjalankan bisnis yang fokus terutama pada perbaikan pelayanan pada pelanggan yang sudah ada dibandingkan dengan mencari pelanggan baru. Dari definisi tersebut maka dapat dikatakan bahwa relationship marketing adalah upaya mengenal konsumen lebih baik, sehingga perusahaan dapat memenuhi needs and wants mereka dalam jangka panjang (Zeithmal dkk., 2006:138).

Tujuan utama relationship marketing sebenarnya adalah untuk menemukan lifetime value dari pelanggan. Setelah lifetime value didapat, tujuan selanjutnya adalah bagaimana agar lifetime value masing-masing kelompok pelanggan dapat terus diperbesar dari tahun ketahun. Setelah itu, tujuan ketiganya adalah bagaimana menggunakan profit yang didapat dari dua tujuan pertama untuk mendapatkan pelanggan baru dengan biaya yang relatif murah. Dengan demikian, tujuan jangka panjangnya adalah menghasilkan keuntungan terus menerus dari dua kelompok pelanggan : pelanggan yang sekarang dan pelanggan baru (Chan S, 2003). Dalam hubungannya denga penelitian ini, relationship marketing dapat diterapkan melalui beberapa strategi pendekatan pelanggan yaitu dengan memberikan manfaat hubungan, meningkatkan nilai yang dirasakan oleh pelanggan, serta meningkatkan kepercayaan pelanggan.

\section{Relational Benefits}

Manfaat Relational atau lebih dikenal dengan relational benefits didefinisikan oleh Gwiner, et al (1998) sebagai manfaat yang didapat pelanggan dari hubungan yang berkesinambungan dan melebihi kinerja jasa inti. Berdasarkan penelitian yang dilakukan oleh Kinard dan Capella, (2006) "Relationship marketing: the influence of consumer involvement on perceived service benefits", Journal of Services Marketing, Vol. 20 Iss: 6, pp.359 - 368 mengatakan bahwa : Manfaat Relasional didefinisikan sebagai manfaat yang diterima pelanggan dari hubungan jangka panjang dan diluar inti kinerja pelayanan ( Gwinner et al., 1998). Secara khusus, Gwinner et al. ( 2003 ) menunjukkan bahwa manfaat relasional ini adalah hasil dari keterlibatan pertukaran relasional dalam jangka panjang dengan perusahaan jasa dan dapat dikategorikan menjadi tiga jenis manfaat yang berbeda yakni confidence benefit, social benefit, dan special treatment benefit.

\section{Perceived Value}

Menurut Kotler 1994 (dalam Tjiptono 2000 : 54) Perceived value adalah penilaian pelanggan terhadap kualitas barang dan jasa secara keseluruhan atas keunggulan suatu jasa 
atau produk seringkali tidak konsisten sehingga pelanggan menggunakan isyarat intrinsik (output dan penyampaian jasa) dan isyarat ekstrinsik (unsur-unsur pelengkap jasa) sebagai acuan.

Aktivitas pemasaran yang dilakukan oleh sebuah peruasahaan tertentu saja bertujuan untuk menyampaikan nilai (Value) yang dimiliki produknya kepada konsumen. Pelanggan adalah Value maximizer, dengan demikian mereka akan membeli dari perusahaan yang mereka pandang akan menawarkan nilai produk yang paling tinggi. Perusahaan dapat menawarkan nilai produknya dari apa yang disebut Customer Delivered Value. (Kotler, 2003).

Pelanggan dalam menentukan pilihannya terhadap suatu produk atau jasa sangat memperhatikan nilai (value) yang akan diterimanya. Produk dan jasa yang menawarkan nilai yang diterima pelanggan (customer delivered value) yang tertinggilah yang akan dipilih pelanggan. Nilai yang dapat dirasakan pelanggan (customer perceived value) di definisikan sebagai selisih antara manfaat yang diperoleh dengan pengorbanan yang dikeluarkan pelanggan (Slater, 1997 : Berry dan Yadav, 1996 ; Ravald dan Gronroos, 1996) untuk memenuhi ekspetasi dalam pemenuhan kebutuhan.

Acuan perceived value dalam penelitian ini merupakan hasil modifikasi dari Jirawat dan Panisa (2009) ; Patrick (2002); yang didefinisikan sebagai nilai yang dirasakan pelanggan, yang berkenaan dengan ; Quality, penilaian tentang keunggulan penyedia jasa Miracle Aesthetic Clinic secara keseluruhan oleh pelanggan. Emotional response, penilaian pelanggan yang menggambarkan tentang kesenangan, kegembiraan serta emosi positif yang ditimbulkan dari menggunakan produk dan jasa Miracle Aesthetic Clinic. Monetary price, penilaian pelanggan yakni manfaat yang diperoleh dari persepsi terhadap kualitas dan kinerja yang diharapkan atas produk. Behavioral price, penilaian pelanggan berdasarkan pengorbanan untuk memperoleh layanan dari Miracle Clinic dilihat dari segi waktu dan usaha untuk mendapatkan layanan tersebut. Reputation, penilaian pelanggan berdasarkan status dari jasa yang dirasakan oleh pelanggan berdasarkan citra perusahaan.

\section{Trust}

Kepercayaan adalah faktor penting dalam membangun komitmen antara perusahaan dan pelanggan. Kepercayaan menurut Lau dan Lee (1999) sebagai kesediaan (willingness) seseorang untuk menggantungkan dirinya pada orang lain dengan besaran risiko tertentu. Kepercayaan terhadap merek pada benak pelanggan terbentuk dari pengalaman masa lalu serta interaksi sebelumnya (Garbarino dan Johnson, 1999). Kepercayaan akan terjadi pada suatu kelompok bila suatu tindakan kelompok lain akan memberikan hasil positif baginya. Donney dan Cannon dalam Aydin dan Ozer (2005) menyatakan bahwa kepercayaan merupakan suatu proses menghitung (calculative process) antara biaya yang dikeluarkan dengan hasil yang diperoleh. Menurut teori Trust Commitment (Morgan dan Hunt, 1994), kepercayaan merupakan kunci untuk menjaga dan memelihara hubungan jangka panjang.

Menurut Mayer et al. (1995) faktor yang membentuk kepercayaan seseorang terhadap yang lain ada tiga yaitu kemampuan (ability), kebaikan hati (benevolence), dan integritas (integrity).

\section{Loyalitas Pelanggan}

Loyalitas pelanggan merupakan suatu konsep yang sangat penting di dalam pemasaran, khususnya dalam kondisi pasar dengan tingkat pertumbuhan yang rendah tapi tingkat persaingan ketat. Banyak perusahaan menyadari bahwa kegiatan mempertahankan pelanggan lebih memberikan keuntungan dibandingkan jika perusahaan harus menarik pelanggan baru lagi. Orientasi jangka panjang yang menekankan komitmen pada pelanggan menjadi hal yang amat penting dan harus diperhatikan oleh perusahaan. Menurut Griffin yang dikutip oleh Dwi Kartini Yahya (2005:31) mengungkapkan karakteristik konsumen yang loyal adalah sebagai berikut ;melakukan pembelian ulang secara teratur (makes reguler repeat purchase). Loyalitas lebih mengacu pada wujud perilaku dari unit-unit pengambilan keputusan untuk melakukan pembelian secara terus menerus terhadap barang atau jasa suatu perusahaan yang dipilih. Tingkat kepuasan terhadap toko akan mempengaruhi mereka untuk membeli kembali, membeli diluar lini produk atau jasa (purchases across product and service lines). Membeli di luar lini produk dan jasa artinya keinginan untuk membeli lebih dari produk dan jasa yang telah ditawarkan oleh perusahaan. Pelanggan yang sudah percaya pada perusahaan dalam suatu 
urusan maka akan percaya juga untuk urusan lain, mereferensikan kepada orang lain, artinya menarik pelanggan baru untuk perusahaan (Refers other). Pelanggan yang loyal dengan sukarela merekomendasikan perusahaan kepada teman-teman dan rekannya, menunjukkan kekebalan daya tarik dari pesaing (Demonstrates an immunity to the full of the competition). Tidak mudah terpengaruh oleh tarikan persaingan perusahaan sejenis lainnya.

\section{KERANGKA KONSEPTUAL Konsep Penelitian}

Pada penelitian ini digunakan penelitian digunakan model penelitian Po-Tsang Chen dan Hsin-Hui $\mathrm{Hu}$ (2010) menggunakan relational benefit dan perceived value serta loyalitas sebagai veriabel dependen dan indepennya. Penambahan variabel trust diadaptasi dari penelitian Liliana Bove (2005) yang meneliti relational benefits kaitannya dengan trust. Penambahan variabel trust yang dikaitkan dengan perceived value diadaptasi dari penelitian Jirawat Anuwichanont dan Panisa Mechinda (2009). Menurut penelitian Chinomona dan Maxwell Sandada (2013) trust dapat secara langsung mempengaruhi loyalitas pelanggan. Semakin tinggi trust maka akan semakin tinggi loyalitas pelanggan yang diperoleh oleh penyedia jasa.
Semakin berkembangnya bisnis klinik kecantikan aesthetic yang mengkhususkan pada perawatan kulit wajah merupakan hal yang melatarbelakangi penelitian ini. Dalam penelitian yang dilakukan oleh Chen dan $\mathrm{Hu}$ (2010) menjelaskan semakin banyak manfaat yang diterima pelanggan, maka semakin besar nilai yang dirasakan oleh pelanggan. Apabila manfaat yang diterima oleh pelanggan dapat tersampaikan dengan baik maka akan berakibat pada loyalitas pelanggan. Pada penelitian terdahulu oleh Heng Chen (2011) dan Jirawat (2009) mengungkapkan bahwa semakin besar manfaat yang diterima dan nilai yang dirasakan terhadap jasa tersebut semakin besar maka akan memperkuat trust pelanggan untuk jangka panjang, hal tersebut dapat berdampak pada loyalitas pelanggan. Berdasarkan teori dan penelitian terdahulu tersebut peneliti akan menjelaskan hubungan antara manfaat yang diterima pelanggan (relational benefits), nilai yang dirasakan oleh pelanggan (perceived value), yang akan dimediasi oleh kepercayaan pelanggan (trust) sehingga mampu menghasilkan loyalitas pelanggan.

Berdasarkan pemaparan konseptual dan hasil penelitian terdahulu di atas maka kerangka konseptual penelitian ini disajikan sebagai berikut :

\section{Gambar 1. Kerangka konseptual}

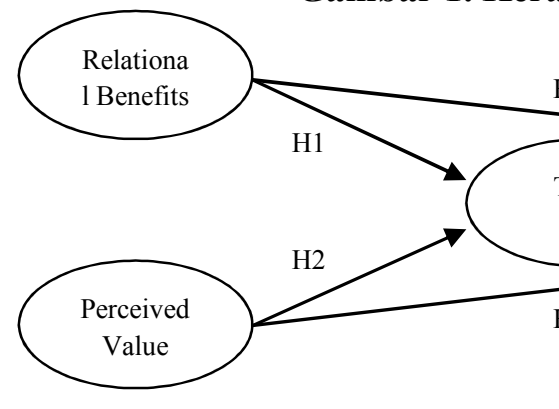

\section{Hipotesis Penelitian}

Adapun hipotesis dalam penelitian ini adalah:

H1 : Relational benefits secara langsung berpengaruh signifikan terhadap trust.

H2 : Perceived value secara langsung berpengaruh signifikan terhadap trust.

H3 : Relational benefits secara langsung berpengaruh signifkan terhadap loyalitas pelanggan.
33

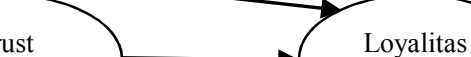
Pelangga

H4 : Perceived value secara langsung berpengaruh signifikan terhadap loyalitas pelanggan.

H5 : Trust secara langsung berpengaruh signifikan terhadap loyalitas pelanggan.

H5 : Relational benefits berpengaruh signifikan terhadap loyalitas pelanggan melalui trust.

H6 : Perceived value berpengaruh signifikan terhadap loyalitas pelanggan melalui trust. 


\section{METODE}

Penelitian ini dilakukan pada pelanggan Miracle Aesthetic Clinic di Jl. Wilis Kota Malang yang telah melakukan transaksi pembelian produk dan sedang mendapatkan pelayanan di Miracle Clinic.

Populasi dalam penelitian ini adalah seluruh pelanggan Miracle Aesthetic di Kota Malang yang telah melakukan transaksi untuk mendapatkan barang maupun jasa pelayanan di klinik kecantikan tersebut. teknik pengambilan sampel yang digunakan masuk dalam kategori non-probability sampling (Sekaran, 1992:235; Black dan Champion, 2001:233; Cooper dan Schindler, 2003:198). Sesuai dengan karakteristik sampel tertentu yang dibutuhkan, yaitu pelanggan Miracle Clinic di Kota Malang yang telah melakukan transaksi dan mengunjungi setiap bulannya, maka teknik pengambilan sampel non-probabilitas yang dipilih adalah teknik purposive sampling.

Dalam penelitian ini, besarnya sampel disesuaikan dengan model analisis yang digunakan yaitu Structural Equation Model (SEM). Berkaitan dengan hal tersebut, ukuran sampel untuk SEM yang menggunakan model estimasi maximum likelihood estimation (MLE) adalah 100-200 sampel (Hair et al., 1998:605; Ghozali, 2004:17), atau sebanyak 5 - $10 \mathrm{kali}$ jumlah parameter yang diestimasi (Ferdinand, 2000:44). Dalam penelitian ini jumlah responden yang diperoleh sebanyak 10 kali jumlah parameter yang diestimasi $(10 \times 13$ parameter). Dari jumlah tersebut yang memenuhi syarat untuk dijadikan sampel sebanyak 130 responden.

\section{HASIL DAN PEMBAHASAN}

Sebelum dilakukan analisis SEM, terlebih dahulu dilakukan uji asumsi yang mendasari model SEM yaitu normalitas, outlier, dan linieritas. Hasil Pengujian asumsi normalitas multivariate menunjukkan bahwa secara multivariate data telah berdistribusi normal. Hal ini diindikasikan pada nilai statistic skewness sebesar -0.104 (critical ratio sebesar -0.52) dengan nilai kritis $Z_{\text {hitung }}$ untuk $\alpha 5 \%$ adalah sebesar 1.96 dan nilai statistic Kurtosis sebesar -0,628 (critical ratio sebesar -1.57) dengan nilai kritis $Z_{\text {hitung }}$ untuk $\alpha 5 \%$ adalah sebesar 1.96. Karena nilai mutlak CR masingmasing untuk skewness dan kurtosis sebesar $0.52<1.96$ dan $1.57<1.96$, maka asumsi normalitas multivariate telah terpenuhi.

Untuk menguji ada tidaknya outlier, dapat dilihat dengan mahalanobis distance (Md). Mahalanobis distance dievaluasi menggunakan nilai 94.460. Dari jarak Mahalanobis dengan titik observasi yang paling jauh adalah responden ke 86 dengan nilai $\mathrm{Md}=36.776$. Jika dibandingkan dengan nilai 94.460 maka nilai Md titik ke-86 < 94.460, maka disimpulkan bahwa semua titik observasi bukan merupakan outlier.

Pengujian asumsi linieritas dilakukan dengan metode Curve Fit. Hasil pengujian linieritas menunjukkan semua model linier signifikan karena nilai Sig $<0.05$ sehingga disimpulkan bahwa asumsi linieritas telah terpenuhi.

\section{Goodness Of Fit}

Hasil pengujian goodness of fit overall model, sesuai dengan hasil analisis SEM, guna mengetahui apakah model hipotetik didukung oleh data empirik, diberikan pada Tabel berikut:

\section{Hasil Pengujian Goodness Of Fit Overall Model}

\begin{tabular}{|c|c|c|c|}
\hline Konstruk & AVE & Composite Reliability & Cronbachs Alpha \\
\hline X1 & 0.5278 & 0.8858 & 0.8495 \\
\hline X2 & 0.5243 & 0.9161 & 0.8978 \\
\hline Y1 & 0.5159 & 0.8814 & 0.8429 \\
\hline Y2 & 0.6262 & 0.8931 & 0.85 \\
\hline
\end{tabular}

Sumber: Data Primer Diolah, 2016

Nilai AVE untuk keempat konstruk tersebut lebih besar dari 0,5 sehingga dapat disimpulkan bahwa evaluasi pengukuran model memiliki diskriminan validity yang baik.
Disamping uji validitas konstruk, dilakukan juga uji reliabilitas konstruk yang diukur dengan uji kriteria yaitu composite reliability dan cronbach alpha dari blok indikator yang mengukur konstruk. Konstruk 
yang dinyatakan reliable jika nilai composite reliability maupun cronbach alpha di atas 0.70 . Jadi dapat disimpulkan bahwa konstruk memiliki reliabilitas yang baik.

\section{Analisis Structural Equation Modeling (SEM)}

Dalam model struktural ini, diuji 7 (tujuh) hipotesis hubungan antar variabel (pengaruh langsung). Berikut disajikan secara lengkap hasil pengujian hubungan antar variabel penelitian sebagai berikut:
Pada tabel di atas dapat dilihat bahwa bobot terbesar untuk total effect adalah pengaruh antara Relational Benefits terhadap trust dengan bobot 5,234. Selain pengujian pengaruh langsung, pada SEM juga dikenal pengaruh tidak langsung (indirect effect). Pengaruh tidak langsung adalah hasil perkalian 2 (dua) pengaruh langsung. Pengaruh tidak langsung dinyatakan signifikan jika kedua pengaruh langsung yang membentuknya adalah signifikan.

Model Struktural Hasil SEM: Pengaruh Langsung

\begin{tabular}{|l|c|c|c|}
\hline \multicolumn{1}{|c|}{ Hipotesis } & t-Statistik & t-Tabel & Keterangan \\
\hline Hipotesis 1: Relational Benefits -> Trust & 5,234 & 1,960 & $\begin{array}{c}\text { Hipotesis 1 } \\
\text { diterima }\end{array}$ \\
\hline Hipotesis 2 : Perceived Value -> Trust & 5,156 & 1,960 & $\begin{array}{c}\text { Hipotesis 2 } \\
\text { diterima }\end{array}$ \\
\hline Hipotesis 3 : Relational Benefits -> Loyalitas & 2,724 & 1,960 & $\begin{array}{c}\text { Hipotesis 3 } \\
\text { diterima }\end{array}$ \\
\hline Hipotesis 4 : Perceived Value -> Loyalitas & 2,945 & 1,960 & $\begin{array}{c}\text { Hipotesis 4 } \\
\text { diterima }\end{array}$ \\
\hline Hipotesis 5 : Trust -> Loyalitas & 2,507 & 1,960 & $\begin{array}{c}\text { Hipotesis 5 } \\
\text { diterima }\end{array}$ \\
\hline Hipotesis 6 : Relational Benefits -> Trust -> Loyalitas & 2,556 & 1,960 & $\begin{array}{c}\text { Hipotesis 6 } \\
\text { diterima }\end{array}$ \\
\hline Hipotesis 7 : Perceived Value -> Trust -> Loyalitas & 2,727 & 1,960 & $\begin{array}{c}\text { Hipotesis 7 } \\
\text { diterima }\end{array}$ \\
\hline
\end{tabular}

Sumber: Data Primer Diolah, 2016

Model Struktural Hasil SEM: Pengaruh Tidak Langsung
\begin{tabular}{|c|c|c|c|c|c|c|c|}
\hline Varaibel & \multicolumn{2}{|c|}{ Koefisien Langsung } & \multicolumn{2}{c|}{ standar error } & Koefisien TL & se Gab & t Hitung \\
\hline $\mathrm{X}_{1}, \mathrm{Y}_{1}, \mathrm{Y}_{2}$ & 0.422 & 0.281 & 0.081 & 0.112 & 0.1186 & 0.0464 & 2.5569 \\
\hline $\mathrm{X}_{2}, \mathrm{Y}_{1}, \mathrm{Y}_{2}$ & 0.414 & 0.281 & 0.069 & 0.112 & 0.1163 & 0.0427 & 2.7273 \\
\hline
\end{tabular}

\section{Pembahasan Hasil Penelitian}

Relational benefits berpengaruh positif secara langsung dan signifikan terhadap trust pada pelanggan Miracle Aesthetic Clinic Malang.

Nilai variabel relational benefits terhadap trust dengan koefisien jalur sebesar 0,422 dan $\mathrm{t}$ statistik sebesar 5,234 nilai tersebut lebih besar dari t tabel $(1,960)$ pada $p \leq 0,05 \%$. Dari hasil diatas menunjukkan bahwa $\mathrm{HO}$ ditolak dan $\mathrm{H} 1$ diterima hal ini berarti hipotesis pertama diterima.

Pada hipotesis penelitian ini menunjukkan hasil yang sama dengan penelitian yang dilakukan oleh Liliana Bove (2005) bahwa keseluruhan dimensi relational benefits memiliki pengaruh positif secara langsung dan signifikan terhadap trust. Hal ini dapat dijelaskan bahwa manfaat hubungan antara penyedia jasa dengan pelanggan Miracle Clinic yang berlangsung dalam jangka panjang akan menstimulasi kepercayaan pelanggan terhadap penyedia jasa, karena keuntungan yang diterima dari hubungan jangka panjang tersebut.

Perceived value berpengaruh positif secara langsung dan signifikan terhadap trust pada pelanggan Miracle Aesthetic Clinic Malang.

Dari hasil olah data menggunakan SmartPLS didapatkan nilai original sampel (O) yang merupakan nilai koefisien jalur dan nilai $t$ statistik untuk menunjukkan signifikansinya. Hasil pengujian hipotesis kedua menunjukkan bahwa hubungan variabel perceived value dengan trust menunjukkan nilai koefisien jalur sebesar 0,414 dengan nilai $t$ statistik sebesar 5,156 . Nilai tersebut lebih besar dari t tabel 
$(1,960)$ dan signifikan pada $\mathrm{p} \leq 0,05 \%$. Dari hasil diatas menunjukkan bahwa $\mathrm{H} 0$ ditolak dan H1 diterima hal ini berarti hipotesis kedua diterima.

Hasil hipotesis penelitian ini mendukung hasil penelitian sebelumnya yang dilakukan oleh Hasan dan Kiong (2014) serta penelitian Oktora dan Achyar (2014) bahwa perceived value memiliki pengaruh positif secara langsung dan signifikan terhadap trust. Kepercayaan pelanggan merupakan elemen kunci dalam mengembangkan hubungan jangka panjang dengan pelanggan ketika pelanggan merasakan manfaat, menerima manfaat lebih tinggi dari pada biaya yang dikorbankan untuk mendapatkan manfaat tersebut, pelanggan akan lebih cenderung menempatkan kepercayaan pada penyedia layanan serta memelihara hubungan.

\section{Relational benefits berpengaruh positif secara} langsung dan signifikan terhadap loyalitas pelanggan Miracle Aesthetic Clinic Malang.

Relational benefits memiliki pengaruh positif terhadap loyalitas pelanggan dengan koefisien jalur sebesar 0,278 dan $\mathrm{t}$ statistik sebesar 2,724 lebih besar dari t tabel $(1,960)$ dan signifikan pada $\mathrm{p} \leq 0,05 \%$. Dari hasil diatas menunjukkan bahwa $\mathrm{H} 0$ ditolak dan $\mathrm{H} 1$ diterima hal ini berarti hipotesis ketiga diterima.

Hasil hipotesis pada penelitian ini mendukung hasil penelitian sebelumnya yang dilakukan oleh Feng Xi dan Zhang Mingli (2013) dan penelitian Chen dan $\mathrm{Hu}$ (2010). Pelanggan yang mengembangkan hubungan jangka panjang dengan penyedia jasa selain manfaat non materi, manfaat lainnya seperti layanan yang lebih cepat serta layanan yang premium hal tersebut mampu meningkatkan loyalitas pelanggan selama jangka panjang.

\section{Perceived value berpengaruh positif secara langsung dan signifikan terhadap loyalitas pelanggan Miracle Aesthetic Clinic Malang. \\ Perceived value memiliki pengaruh positif terhadap loyalitas pelanggan dengan koefisien jalur sebesar 0,323 dan t statistik sebesar 2,945 lebih besar dari $\mathrm{t}$ tabel $(1,960)$ dan signifikan pada $\mathrm{p} \leq 0,05 \%$. Dari hasil diatas menunjukkan bahwa $\mathrm{H} 0$ ditolak dan $\mathrm{H} 1$ diterima hal ini berarti hipotesis keempat diterima.}

Hasil hipotesis ini mendukung hasil penelitian yang telah dilakukan oleh Chen dan $\mathrm{Hu}$ (2010), Harris dan Goode (2004). Seperti penelitian yang telah dilakukan sebelumnya bahwa perceived value memainkan peran penting dalam mempengaruhi loyalitas pelanggan. Temuan penelitian ini mengungkapkan bahwa nilai simbolik dimensi dari perceived value dapat menyebabkan bagaimana pelanggan dapat meningkatkan apa yang dirasakan dan diterima pelanggan, tentang bagaimana mereka mendapatkan kepuasaan serta reputasi yang baik menciptakan persepsi dari nilai yang dirasakan pelanggan melampaui nilai fungsional yang dapat mempengaruhi loyalitas pelanggan.

Trust berpengaruh positif secara langsung dan signifikan terhadap loyalitas pelanggan Miracle Clinic Malang.

Trust memiliki pengaruh positif terhadap loyalitas pelanggan dengan koefisien jalur sebesar 0,281 dan t statistik sebesar 2,507 lebih besar dari $t$ tabel $(1,960)$ dan signifikan pada $\mathrm{p} \leq$ $0,05 \%$. Dari hasil diatas menunjukkan bahwa H0 ditolak dan $\mathrm{H} 1$ diterima hal ini berarti hipotesis kelima diterima.

Hasil hipotesis pada penelitian ini mendukung hasil penelitian sebelumnya yang dilakukan oleh Richard Chinomona dan Maxwell Sandada (2013), Muzahid Akbar dan Noorjahan Parvez (2009), Harris dan Goode (2004). Ketika penyedia layanan membangun kepercayaan pelanggan. maka pelanggan akan menganggap resiko terhadap kegagalan akan rendah dan akan lebih percaya pada integritas penyedia layanan. Hal ini akan berdampak pada semakin loyal pelanggan lama maupun pelanggan baru.

Trust memediasi hubungan antara relational benefits dengan loyalitas pelanggan Miracle Aesthetic Clinic Malang.

Hasil pengujian hipotesis keenam menunjukkan bahwa hubungan variabel relational benefits dengan Loyalitas Pelanggan (Y2) melalui trust menunjukkan nilai koefisien jalur tidak langsung sebesar 0,1186 dengan nilai t statistik sebesar 2,5569. Nilai tersebut lebih besar dari t tabel $(1,960)$. Hasil ini berarti bahwa trust memiliki pengaruh yang signifikan dalam menjembatani relational benefits terhadap Loyalitas Pelanggan. Hasil diatas menunjukkan bahwa $\mathrm{H} 0$ ditolak dan $\mathrm{H} 1$ diterima hal ini berarti Hipotesis 6 diterima.

Melihat hasil hipotesis enam ini, dapat dijelaskan bahwa trust memiliki pengaruh besar dalam penelitian ini karena trust mampu menguhubungkan antara relational benefits 
dengan loyalitas pelanggan. Mediasi ini merupakan hubungan mediasi parsial karena tanpa adanya mediasi dari trust, variable relational benefit memiliki pengaruh pada loyalitas secara langsung. Hipotesis enam ini membuka jalan bagaimana penyedia jasa menciptakan kepercayaan pelanggan untuk mempertahankan loyalitas pelanggan dalam jangka panjang.

Trust memediasi hubungan antara perceived
value dan loyalitas pelanggan Miracle
Aesthetic Clinic Malang.
Hasil pengujian hipotesis ketujuh menunjukkan bahwa hubungan variabel perceived value dengan Loyalitas Pelanggan (Y2) melalui trust menunjukkan nilai koefisien jalur tidak langsung sebesar 0,1163 dengan nilai t statistik sebesar 2,727. Nilai tersebut lebih besar dari t tabel $(1,960)$. Hasil ini berarti bahwa trust memiliki pengaruh yang signifikan dalam menjembatani perceived value terhadap loyalitas pelanggan. Hasil diatas menunjukkan bahwa $\mathrm{H} 0$ ditolak dan $\mathrm{H} 1$ diterima hal ini berarti Hipotesis 7 diterima. Hubungan mediasi ini merupakan mediasi parsial karena tanpa adanya mediasi dari trust, varibel perceived value memiliki pengaruh terhadap loyalitas pelanggan.

Hasil hipotesis ketujuh ini menunjukkan bahwa tidak cukup hanya dengan perceived value maka pelanggan akan loyal. Dengan meningkatkan kepercayaan pelanggan artinya pelanggan percaya pada pelayanan Miracle Clinic yang kompeten dan dapat diandalkan untuk dapat memberikan hasil yang diinginkan pelanggan. Hal tersebut mampu menciptakan loyalitas pelanggan dalam jangka panjang.

Berdasarkan penjelasan mengenai pengaruh maupun pengaruh tidak langsung terhadap loyalitas pelanggan, di dapatkan bahwa Relational Benefits maupun perceived value memberikan pengaruh secara langsung terhadap Loyalitas Pelanggan. Disamping itu Relational Benefits maupun perceived value juga memberikan pegnaruh secara tidak langsung terhadap Loyalitas pelanggan yang melalui Trust.

\section{Keterbatasan Penelitian}

Dalam penelitian ini secara umum berusaha menjawab perumusan dan tujuan penelitian, namun terdapat keterbatasan dalam penelitian ini yaitu:
1. Penelitian ini hanya dilakukan pada pelanggan Miracle Clinic di Kota Malang yang pada saat itu berkunjung di klinik kecantikan Miracle Malang. Diharapkan pada penelitian yang akan datang dapat dilakukan penelitian dengan area yang lebih besar.

2. Penelitian ini tentunya mengandung keterbatasan-keterbatasan. Diantaranya adalah dalam penelitian ini masih belum memasukkan seluruh indikator variabel trust dan perceived velue yang dikemukakan oleh beberapa peneliti sebelumnya.

3. Selain itu, meskipun jumlah sampel sudah memenuhi asumsi SEM, tetapi masih perlu diperbesar sehingga hasilnya dapat digunakan untuk mengeneralisir kondisi pelanggan Miracle Aesthetic Clinic.

\section{Kesimpulan}

Berdasarkan hasil analisis dan pembahasan dalam penelitian ini maka dapat diambil kesimpulan bahwa:

1. Relational benefits memiliki pengaruh secara langsung terhadap trust (kepercayaan) pelanggan. Relational benefits yang terdiri atas indikator confidence benefit, social benefit, special treatment benefit menunjukkan memiliki peranan penting terhadap kepercayaan (trust) pelanggan. Indikator confidence benefit memiliki prioritas tertinggi dalam peranannya untuk meningkatkan kepercayaan pelanggan Miracle Aesthetic Malang.

2. Perceived value berpengaruh secara langsung terhadap trust (kepercayaan) pelanggan. Perceived value yang terdiri atas indikator reputation, quality, emotional responses, monetary price, behavioral price. Indikator reputation memiliki pengaruh tertinggi pada peningkatan kepercayaan (trust) pelanggan Miracle Aesthetic Malang.

3. Relational benefits memiliki pengaruh dan peranan dalam peningkatan loyalitas pelanggan Miracle Aesthetic Malang. Terutama pada indikator confidence benefit yang mampu memberikan manfaat rasa kenyamanan melalui karyawan Miracle yang selalu kooperatif dan memberikan kesan yang nyaman serta mampu meyakinkan pelanggan bahwa produk yang digunakan termasuk produk yang aman.

4. Perceived value memiliki pengaruh dan peranan dalam peningkatan loyalitas 
pelanggan Miracle Aesthetic Malang terutama pada indikator reputation.

5. Trust memiliki peran penting dalam meningkatkan loyalitas pelanggan. Indikator yang memiliki kontribusi tertinggi adalah indikator benevolence.

6. Trust memiliki peran penting dalam memediasi secara parsial antara relational benefits terhadap loyalitas pelanggan.

7. Trust memiliki peran penting dalam memediasi secara parsial antara perceived value terhadap loyalitas pelanggan.

\section{Saran}

Berdasarkan analisis hasil peneltian dan pembahasan, dapat dikemukakan beberapa saran sebagai berikut:

1. Saran untuk manajemen Miracle Aesthetic Malang

Miracle Aesthetic Clinic disarankan untuk meningkatkan manfaat hubungan (relational benefits) dan meningkatkan perceived value. Menyadari relational benefits dan perceived value merupakan aspek penting dalam membangun kepercayaan pelanggan dan loyalitas pelanggan, sehingga fokus terhadap menjaga hubungan antara pelanggan dan penyedia jasa terletak pada manfaat hubungan jangka panjang. Sehingga hal tersebut akan berpotensi untuk mempermudah dalam menciptakan pelanggan baru serta mempertahankan pelanggan lama.

Peningkatan pada derajat empati, kesopanan, dan keramahan dalam memberikan layanan, hal ini terutama bagi karyawan yang berinteraksi secara langsung dengan pelanggan, seperti operator telepon, petugas keamanan, customer service, therapist, serta dokter kecantikan yang langsung menangani pelanggan. Hal ini dapat meningkatkan dimensi pada relational benefits yang dirasa masih kurang yaitu social benefits. Mengingat manfaat hubungan pada industri jasa sangat ditentukan oleh orang - orang yang berada di garis depan dalam melayani untuk menciptakan manfaat hubungan yang baik dan mengenal lebih dekat dengan pelanggan.

Penciptaan layanan khusus pribadi, hal ini berkaitan dengan peningkatan salah satu indikator perceived value yaitu emotional responses. Dengan memberikan layanan pribadi maka pelanggan akan menanggapi lingkungan tempat pelanggan menerima manfaat jasa sehingga menstimulus pelanggan untuk menjadikan Miracle Aesthetic Clinic menjadi pilihan utama dalam memilih tempat perawatan kecantikan kulit.

Memberikan kesempatan kepada pelanggan untuk menyampaikan keluhan, karena aktivitas dan jasa kecantikan terkait dengan pemanfaatan obat - obat kecantikan yang mengandung bahan kimia serta dampak secara langsung terhadap pelanggan dalam jangka panjang dan resiko tertentu maka aspek kejujuran sangat diperlukan. Misalnya dengan hotline bebas pulsa, serta penyedia jasa rajin memberikan informasi tambahan dan ter-update seputar perawatan kulit wajah. Maka aspek integritas akan dapat meningkatkan kepercayaan (trust) pelanggan Miracle Aesthetic Clinic.

2. Saran untuk peneliti berikutnya

Pada penelitian berikutnya dapat ditambahkan variable atau indikator baru untuk memperkaya model yang digunakan pada penelitian ini. Dengan demikian, hasil penelitian berikutnya dapat lebih sempurna dan kesimpulan yang diperoleh dapat berbeda atau tetap sama dengan hasil penelitian ini. Misalnya dengan menambahkan variabel citra produk yang berkaitan erat dengan reputasi, karena dalam penelitian ini diketahui bahwa reputasi memiliki peran penting dalam mempengaruhi kepercayaan dan loyalitas pelanggan. Jika memang terbukti hasilnya sama, berarti model yang digunakan dalam penelitian ini mempunyai konsistensi yang tinggi untuk diterapkan di Indonesia.

\section{DAFTAR PUSTAKA}

A. Vincent, N., \& M. Webster, C. (2013). Exploring relationship marketing in membership associations. European Journal of Marketing, 47(10), 16221640.

Akbar, M. M., \& Parvez, N. (2009). Impact of service quality, trust, and customer satisfaction on customers loyalty. ABAC Journal, 29(1).

Anderson, E. W., Fornell, C., \& Mazvancheryl, S. K. (2004). Customer satisfaction and shareholder value. Journal of marketing, 68(4), 172-185.

Anderson, J. C., \& Gerbing, D. W.1988. "Structural equation modeling in practice: a review of recommended 
two-step approach". Psychological Bulletin, 103(3), 411-423.

Anuwichanont, J., \& Mechinda, P. (2011). The impact of perceived value on spa loyalty and its moderating effect of destination equity. Journal of Business \& Economics Research (JBER), 7(12).

Arikunto, S., \& Pendekatan, P. P. S. (2006). Praktek. Jakarta: Rineka Cipta.

Aydin, S., Ozer, G., \& Arasil, O. (2005). Customer loyalty and the effect of switching costs as a moderator variable: A case in the Turkish mobile phone market. Marketing Intelligence \& Planning, 23(1), 89-103.

Bagozzi, R. P., \& Yi, Y. 1988. On the evaluation of structural equation models. Journal of the Academy of Marketing Science, 16(1), 74-94.

Beatty, S. E., Mayer, M., Coleman, J. E., Reynolds, K. E., \& Lee, J. (1996). Customer-sales associate retail relationships. Journal of retailing, 72(3), 223-247.

Berry, L. L., \& Parasuraman, A. 1991. "Marketing services". New York: Free Press.

Black, J. A., \& Champion, D. J. (1976). Methods and issues in social research. John Wiley \& Sons.

Bove, Liliana. 2005. The Impact of Relational Benefits on Customer Trust and Commitment. ANZMAC Journal 2005, University of Melbourne.

C. Richard \& O. Loury.2013. The Impact of Product Quality on Perceived Value, Trust, and Students Intention to Purchase Electronic Gadgets. Mediterranean Journal of Social Sciences, vol 4. No 14, November 2013.

C. Richard \& S. Maxwell. 2013. Customer Satisfaction, Trust and Loyalty as Predictors of Customer Intention to Re-Purchase South African Retailing Industry. Mediterranean Journal of Social Sciences vol. 4, no. 14, November 2013.

Chan, S. 2003, Relationship Marketing: Inovasi Pemasaran yang Membuat Pelanggan Bertekuk Lutut, Jakarta: Penerbit PT Gramedia Pustaka Utama

Chaudhuri, A., \& Holbrook, M. B. (2001). The chain of effects from brand trust and brand affect to brand performance: the role of brand loyalty. Journal of marketing, 65(2), 81-93.

Chen, H. H., \& Gatfield, T. (2011). The effect of expertise of service provider, relational benefit on loyalty-an empirical study of hairstyle franchise system. Journal of International Management Studies, 6(1), 1.

Chen, P. T., \& Hu, H. H. (2010). The effect of relational benefits on perceived value in relation to customer loyalty: An empirical study in the Australian coffee outlets industry. International journal of hospitality management, 29(3), 405-412..

Chen, Y. S., \& Chang, C. H. (2012). Enhance green purchase intentions: The roles of green perceived value, green perceived risk, and green trust. Management Decision, 50(3), 502520.

Chinomona, R., \& Sandada, M. (2013). Customer satisfaction, trust and loyalty as predictors of customer intention to re-purchase South African retailing industry. Mediterranean Journal of Social Sciences, 4(14), 437.

Chumpitaz Caceres, R., \& Paparoidamis, N. G. (2007). Service quality, relationship satisfaction, trust, commitment and business-to-business loyalty. European journal of marketing, 41(7/8), 836-867.

Churchill, G. (2005). Dasar-Dasar Riset Pemasaran Edisi 4 Jilid 2 (Diterjemahkan oleh: Dwi Kartini Yahya).

Comer, J. M., Plank, R. E., Reid, D. A., \& Pullins, E. B. (1999). Methods in Sales Research: Perceived Trust in Business-to-Business Sales: A New Measure. Journal of Personal Selling \& Sales Management, 19(3), 61-71.

Cooper, D. R., \& Schindler, P. S. (2003). Research methods. Boston, MA: Irwin.

Dabholkar, P. A., \& Sheng, X. (2012). Consumer participation in using online recommendation agents: effects on satisfaction, trust, and purchase intentions. The Service Industries Journal, 32(9), 1433-1449.

Dagger, T. S., \& O'Brien, T. K. (2010). Does experience matter? Differences in relationship benefits, satisfaction, trust, commitment and loyalty for 
novice and experienced service users. European Journal of Marketing, 44(9/10), 1528-1552.

Dagger, T. S., Danaher, P. J., \& Gibbs, B. J. (2009). How often versus how long the interplay of contact frequency and relationship duration in customerreported service relationship strength. Journal of Service Research, 11(4), 371-388.

Dharmmesta, B. S. (1999). Loyalitas Pelanggan: Sebuah Kajian Konseptual Sebagai Paduan Bagi Peneliti. Journal of Indonesian Economy and Business, 14(3).

Euromonitor International, “ Penjualan kosmetik Indonesia “. 15 Januari 2014. (www.ekbis.sindonews.com, 2014)

Ferdinand, Augusty. 2000. Structural Equation Modeling dalam Penelitian Manajemen. BP Universitas Diponegoro. Semarang.

Gao, H., \& Liu, D. (2014). Relationship of trustworthiness and relational benefit in electronic catalog markets. Electronic Markets, 24(1), 67-75.

Ghozali, I., 2004. Model Persamaan Struktural: Konsep dan Aplikasi dengan Program AMOS Ver. 5.0. BP Universitas Diponegoro, Semarang

Gill, H., Boies, K., Finegan, J. E. and McNally, J. 2005. Antecedents of trust: Establishing a boundary condition for the relation between propensity to trust and intention to trust. Journal of Business and Psychology, Vol. 19 No. 3, pp. 287-302.

Grayson, K., Johnson, D. and Chen, D.-F. R. 2008. Is Firm Trust Essential in a Trusted Environment? How Trust in the Business Context Influences Customers. Journal of Marketing Research, Vol. 45 No. 2, pp. 241-256.

Griffin, J. (1995). Customer loyalty. ESENSI.

Gronroos, C. 1994. From Marketing Mix to Relationship Marketing: Towards a Paradigm Shift in Marketing. Management Decision, Vol. 32 No. 2, pp. 4-20.

Gwinner, K. P., Bitner, M. J., Brown, S. W., \& Kumar, A. (2005). Service customization through employee adaptiveness. Journal of Service Research, 8(2), 131-148.
Gwinner, K. P., Gremler, D. D., \& Bitner, M. J. (1998). Relational benefits in services industries: the customer's perspective. Journal of the academy of marketing science, 26(2), 101-114.

Hair, J, Black, W, Babin, B, Anderson, R \& Tatham, R 2006, Multivariate data analysis, 6th edn, Pearson Education, Inc, Upper Saddle River, New Jersey.

Harris, L. C., \& Goode, M. M. (2004). The four levels of loyalty and the pivotal role of trust: a study of online service dynamics. Journal of retailing, 80(2), 139-158.

Hartono, J. Abdillah. 2009. Konsep \& Aplikasi PLS (Partial Least Square) untuk Penelitian Empiris. Yogyakarta: BPFE Yogyakarta.

Hauser, J. R. (1988). Note-Competitive price and positioning strategies. Marketing Science, 7(1), 76-91.

Hennig-Thurau, T., Gwinner, K. P., \& Gremler, D. D. (2002). Understanding relationship marketing outcomes an integration of relational benefits and relationship quality. Journal of service research, 4(3), 230-247.

Hoffman, P. N., Griffin, J. W., \& Price, D. L. (1984). Control of axonal caliber by neurofilament transport. The Journal of cell biology, 99(2), 705-714.

Hurriyati, R. (2005). Bauran Pemasaran dan Loyalitas Konsumen: Fokus pada Konsumen Kartu Kredit Perbankan.

Jaya, I. G. N. M., \& Sumertajaya, I. M. (2008). Pemodelan Persamaan Struktural dengan Partial Least Square. Semnas Matematika dan Pendidikan Matematika 2008.

Jogiyanto, H. M., \& Abdillah, W. (2009). Konsep dan aplikasi PLS (Partial Least Square) untuk penelitian empiris. BPFE Fakultas Ekonomika dan Bisnis UGM. Yogyakarta.

Johnson, M. S., Sivadas, E., \& Garbarino, E. (2008). Customer satisfaction, perceived risk and affective commitment: an investigation of directions of influence. Journal of Services Marketing, 22(5), 353-362.

Ju Rebecca Yen, H., \& Gwinner, K. P. (2003). Internet retail customer loyalty: the mediating role of relational benefits. International Journal of Service 
Industry Management, 14(5), 483500.

K. Roland \& H.K. Werner. 2010. Consumer trust in service companies: a multiple mediating analysis. Intitute of Marketing, University of Munich.

Kantamneni, S. P., \& Coulson, K. R. (1996). Measuring perceived value: Findings from preliminary research. Journal of Marketing Management, 6(2), 72-86.

Kantsperger, R., \& Kunz, W. H. (2010). Consumer trust in service companies: a multiple mediating analysis. Managing Service Quality: An International Journal, 20(1), 4-25.

Kim, D., \& Benbasat, I. (2003). Trust-Related Arguments in Internet Stores: A Framework for Evaluation. $J$. Electron. Commerce Res., 4(2), 49-64.

Kinard, B. R., \& Capella, M. L. (2006). Relationship marketing: the influence of consumer involvement on perceived service benefits. Journal of Services Marketing, 20(6), 359-368.

Kotler, P, 1994. Manajemen Pemasaran, Analisis, Implementasi dan Pengendalian . Salemba Empat, Jakarta

Kotler, P. T., \& Lee, N. R. (2009). Up and out of poverty: The social marketing solution. Pearson Prentice Hall.

Kotler, P., \& Armstrong, G. (2010). Principles of marketing. pearson education.

Kotler, P., Keller, K.L. 2005. Marketing Management . Twelfth Edition. Pearson Education Inc.

Lapierre, J. (2000). Customer-perceived value in industrial contexts. Journal of Business \& Industrial Marketing, 15(2/3), 122-145.

Lau, G. T., \& Lee, S. H. (1999). Consumers' trust in a brand and the link to brand loyalty. Journal of Market-Focused Management, 4(4), 341-370.

Lemon, K. N., Rust, R. T., \& Zeithaml, V. A. (2001). What drives customer equity. Marketing Management, 10(1), 20.

Malhotra, N. K., Kim, S. S., \& Patil, A. (2006). Common method variance in IS research: A comparison of alternative approaches and a reanalysis of past research. Management science, 52(12), 1865-1883.

Mayer, R. C., Davis, J. H. and Schoorman, F. D. (1995), An Integrative Model of
Organizational Trust, Academy of Management Review, Vol. 20 No. 3, pp. 709-734.

McDougall, G. H., \& Levesque, T. (2000). Customer satisfaction with services: putting perceived value into the equation. Journal of services marketing, 14(5), 392-410.

Miles, M. P., \& Covin, J. G. (2000). Environmental marketing: A source of reputational, competitive, and financial advantage. Journal of business ethics, 23(3), 299-311.

Molina, A., Martín-Consuegra, D., \& Esteban, Á. (2007). Relational benefits and customer satisfaction in retail banking. International Journal of Bank Marketing, 25(4), 253-271.

Morgan, R. M., \& Hunt, S. D. (1994). The commitment-trust theory of relationship marketing. The journal of marketing, 20-38.

Oktora, K., \& Achyar, A. (2014). The Effect Of Post-Purchased Perceived-Value Towards The Relationship Quality Of Hajj And Umrah Travel Agencies In Indonesia. The South East Asian Journal of Management, 8(1), 29.

Oliver, R. L. (1999). Whence consumer loyalty? the Journal of Marketing, 3344.

Prayoga, I. M. S., Yasa, N. N. K., \& Wardana, M. (2015). Relational Benefits, Kepuasan, Dan Loyalitas Pelanggan Pada Bengkel PT HONDA DEWATA MOTOR. Jurnal Manajemen dan Kewirausahaan (Journal of Management and Entrepreneurship), 17(1), 11-20.

Rangkuti, Fredy. 2003. Measuring Customer Satisfaction: Gaining Customer Relationship Strategy. Cetakan Kedua. Gramedia Pustaka Utama, Jakarta.

Riduwan, K. E. A., \& Engkos, A. (2007). Cara menggunakan dan memakai analisis jalur (path analysis). Penerbit: Alfabeta. Bandung.

Ryals, L., \& Knox, S. (2001). Cross-functional issues in the implementation of relationship marketing through customer relationship management. European management journal, 19(5), 534-542. 
S. J. and Deans K. R. 2003. Consumer relational benefits and switching costs in Internet-based electronic markets: a conceptual exploration. Journal of University of Otago. Online Marketing Track.

Schoorman, F. D., Mayer, R. C., \& Davis, J. H. (2007). An integrative model of organizational trust: Past, present, and future. Academy of Management review, 32(2), 344-354.

Sheth, J.N. and A.Parvatuyar(1995). The evolution of relationship marketing. International Business Review, 4(4), 397-418.

Singarimbun, M. Effendi. 2006. Metode Penelitian Survei.

Sirdeshmukh, D., Singh, J., \& Sabol, B. (2002). Consumer trust, value, and loyalty in relational exchanges. Journal of marketing, 66(1), 15-37.

Smith, R. E., \& Wright, W. F. (2004). Determinants of customer loyalty and financial performance. Journal of management accounting research, 16(1), 183-205.

Stanton, M. (2005). Relapse prevention needs more emphasis on interpersonal factors.

Sugiyono, S. (2009). Metode Penelitian Kualitatif. Bandung: CV Alfabeta.

Sugiyono. 2008. Statistik untuk Penelitian. Bandung: CV Alfabeta. Thomas, O.O., Petersen

Sweeney, J. C., \& Soutar, G. N. 2001. Consumer perceived value: The development of a multiple item scale. Journal of Retailing, 77(2): 203-220.

T.K. Hean \& X. Yi.2009. Corporate reputation and customer behavioral intentions: The role of trust, identification, and commitment. Industrial Marketing Management 38(2009), 732-742.

Teo, P. K. (2013). The effects of perceived value and trust on customer loyalty and mediating effects of customer satisfaction: A study of foreign banks in Kota Kinabalu Sabah (Doctoral dissertation, Universiti Malaysia Sabah).

Tjiptono, F. (2005). Pemasaran Jasa, edisi pertama, cetakan pertama. Malang: BayuMedia Publishing.

Velnampy, T., \& S Sivesan, P. (2012). Customer Relationship Marketing and Customer
Satisfaction: A Study on Mobile Service Providing Companies in Sri Lanka. Global journal of management and business research, 12(18).

Wai, C.H.,Lu,T.H.,Ngoh.,TB.,\& Jin.,W.P. 2012. The Effect of Service Quality. Relational Benefits, Perceived Value and Customer Satisfaction Towards Customer Loyalty in Hair Salon Industry. Bachelor of International Business. Universiti Tunku Abdul Rahman.

Wibowo, S., 2006. Implementasi Releationship Marketing Pada Industri Hospitality. Utilitas, Vol 14 No 2, Juni, Hal 178196.

Wiedenfels, G. 2009. Trust of potential buyers in new entrepreneurial ventures. Gabler, Wiesbaden: $G W V$ Faceverlage $\mathrm{GmbH}$.

Wilson, A., Zeithaml, V. A., Bitner, M. J., \& Gremler, D. D. (2012). Services marketing: Integrating customer focus across the firm. McGraw Hill.

Wulf, K. D., Odekerken-Schröder, G., \& Iacobucci, D. (2001). Investments in consumer relationships: A crosscountry and cross-industry exploration. Journal of marketing, 65(4), 33-50.

Xi, F., \& Mingli, Z. (2013). Personality Traits, Relational Benefits and Customer Loyalty: An Empirical Study in Service Context. Journal of Convergence Information Technology, $8(10), 691$.

Zeithaml, V. A. (1988). Consumer perceptions of price, quality, and value: a meansend model and synthesis of evidence. The Journal of marketing, 2-22.

Zeithaml, V. A., Berry, L. L., \& Parasuraman, A. (1996). The behavioral consequences of service quality. the Journal of Marketing, 31-46.

Zheithaml, V. A., Bitner, M. J., \& Gremler, D. D. (2006). Service marketing: Integrating customer focus across the firm. 4th Edition. New York: McGraw Hill. 